the French Commissariat à I'Energie Atomique, the French Institut National des Sciences de I'Univers, the European Geosciences Union, the Belgian Agency for Radioactive Waste and Enriched Fissile Materials, and the Belgian private company "Vincotte". Early career scientists and scientists from Eastern and developing countries were supported by PAGES and EGU.

\section{References}

Lisiecki, L.E. and Raymo, M.E. 2005: A Pliocene-Pleistocene stack of 57 globally distributed benthic $\delta^{18} 0$ records, Paleoceanography, 20 PA1003, doi:10.1029/2004PA001071
Lisiecki, LE and Raymo, M E 2007: Plio-Pleistocene climate evolution: trends and transitions in glacial cycle dynamics, Quaternary Science Reviews, 26: 56-69.

Laskar, J., Robutel1, P., Joutel1, F., Gastineau, M., Correia, A.C.M. and Levrard B., 2004: A long term numberical solution for the insolation quantities of the Earth, Astronomy and Astrophysics, 428 261-185.

\title{
CLIVAR-PAGES-WCRP summer school on El Niño
}

\section{Puna, USA, 14-24 June 2008}

\section{Axel Timmermann}

International Pacific Research Center, University of Hawaii, Honolulu; axel@hawaii.edu

The summer school "ENSO Dynamics and Predictability" took place in the lush jungle of Puna on the Big Island of Hawai'i. Sixteen graduate students in oceanography, meteorology and geology from 10 countries gathered to learn from lecturers on a broad range of ENSO-related topics: ENSO theory (Fei-Fei Jin, University of Hawai'i, USA), ENSO phenomenology (Michael McPhaden, NOAA, USA), ENSO predictability (Magdalena Balmaseda, European Centre for Medium-range Weather Forecasts, UK; Richard Kleeman, Courant Institute, USA), and ENSO's sensitivity to past and future climate change (Scott Power, Centre for Australian Weather and Climate Research Bureau of Meteorology/CSIRO, Australia; Axel Timmermann, University of Hawai'i, USA).

Energized by fresh goat milk kefir, exotic local fruit smoothies and island-style cuisine, the students conducted research projects in addition to the 3-4 hour daily lecture-marathon. In teams, they studied the effects of ENSO on the Antarctic Peninsula, the rapid termination of the 2008 La Niña event that was induced by easterly wind bursts, the geographical reaches of a tropical megadrought $4.2 \mathrm{kyr}$ ago, the effects of state-dependent noise on the predictability of ENSO, the dynamics of warm pool El Niño events, the effects of Atlantic multi-decadal SST variability on ENSO, and the role of equatorial waves in the ENSO recharge mechanism. In carrying out these research projects students applied the concepts taught during the lectures, such as the recharge oscillator paradigm, ENSO frequency entrainment, equatorial waves, basin modes, teleconnection patterns and multiplicative noise.

Understanding ENSO's past requires an in-depth understanding of the coupled instability mechanisms that underlie ENSO and the annual cycle in the eastern equatorial Pacific. Oversimplified concepts, such as the dynamical thermostat, can mislead paleo-proxy interpretations, and a thorough heat-budget analysis of corresponding model simulations is usually needed to understand ENSO changes that occurred with past climate forcings, such as orbitally induced variations in solar insolation. Numerous coupled general circulation model studies have demonstrated that for certain ENSO regimes a weaker (stronger) annual cycle corresponds to stronger (weaker) ENSO variability. Testing these model-derived relations with paleo-proxy data, such as corals, lake records, speleothems, mollusks, and tree rings, would be an important contribution towards a better understanding of ENSO forcing mechanisms in the past.

The summer school demonstrated the benefit for climate research of the CLI-
VAR/PAGES Interaction: Climate modelers need paleo-records to validate their models; paleoclimatologists benefit from the dynamical insights provided by climate modeling experiments. An example of a student team project that highlighted this was provided by Intan Nurhati (Georgia Institute of Technology, USA) and Gabriel Bayona (EAFIT University, Columbia). They studied the geographical extent of a 30 - to 50-year-long megadrought that occurred $\sim 4.2 \mathrm{kyr}$ ago and affected the civilizations of Egypt and Mesopotamia. By compiling and synthesizing paleo-data, from archives such as speleothems, lake sediments and ice cores, they derived a map showing the tropical-wide extent of the drought (Fig. 1). To determine what may have caused this drought, they analyzed cosmogenic isotope variations and temperature variability in the N. Atlantic. Results, however, are still inconclusive. Fostering such joint PAGES/CLIVAR activities could become an important legacy of both programs.

\section{Note}

Lectures are available from: http://iprc.soest.hawaii.edu/ axel/ENSOsummerschool.html

\section{Acknowledgements}

The summer school was supported by PAGES, CLIVAR, WCRP, NOAA, the Australian Government (ARCNESS) and the International Pacific Research Center.

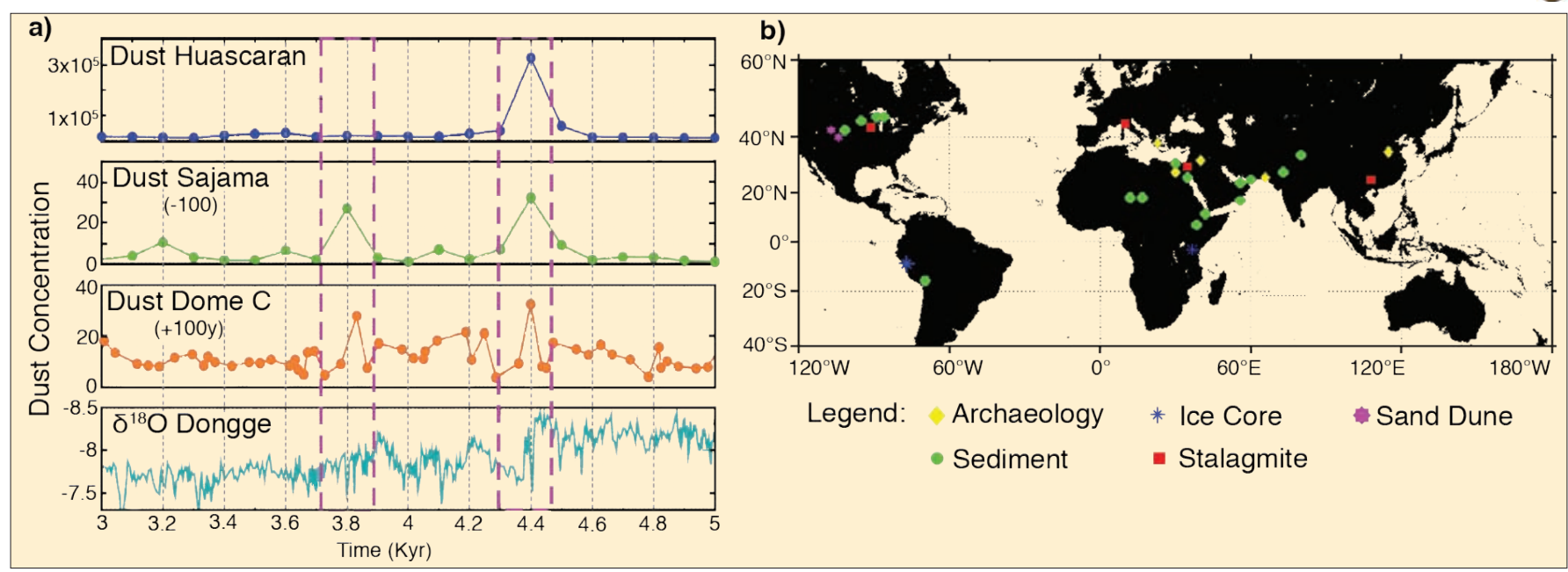

Figure 1:a) Time series of dust fluxes at Huascaran (Peru), Sajama (Bolivia) (timescale shifted by-100 years), EPICA Dome C (Antarctica) (timescale shifted by +100 years) and Dongge Cave $\delta^{18} \mathrm{O}$ (China), indicating major drought periods around the tropics (purple boxes). Dust records indicate that in fact two major droughts occurred around $3.8 \mathrm{kyr}$ and $4.4 \mathrm{kyr}$ BP. In archeological literature, this is often just referred to as the "4.2 kyr event". $\boldsymbol{b}$ ) Extent of the 4.2-kyr-drought event, as derived from different paleo-archives. 